\title{
EFEKTIFITAS MEKANISME KOPING TERHADAP TINGKAT KECEMASAN PADA PASIEN GAGAL GINJAL KRONIK DALAM MENJALANI \\ TERAPI HEMODIALISA DI RUANG HEMODIALISA RSUD. dr. PIRNGADI MEDAN \\ TAHUN 2020
}

\author{
Megawati \\ Poltekkes Kemenkes Medan \\ Email:megawati_medan@gmail.com
}

\begin{abstract}
ABSTRAK
Gagal ginjal kronik makin banyak menarik perhatian dan makin banyak dipelajari, karena walaupun sudah mencapai tahap gagal ginjal terminal, penderita masih dapat hidup panjang dengan kualitas hidup yang cukup baik bahkan baik. Yang disebut dengan gagal ginjal terminal adalah keadan dimana ginjal sudah tidak dapat menjalankan fungsinya lagi. (Lumenta, 1992).

Mekanisme koping adalah cara yang dilakukan individu dalam menyelesaikan masalah, menyesuaikan diri dengan perubahan, serta respon terhadap situasi yang mengancam. Dalam melakukan terapi hemodialisa pada pasien gagal ginjal kronik yang sering dijumpai adalah cemas atau kecemasan. Kecemasan kekhawatiran yang tidak jelas dan menyebar, yang berkaitan dengan penyebaran yang tidak pasti dan tidak berdaya serta keadaan emosi yang tidak memiliki objek spesifik. Tujuan penelitian ini adalah untuk mengetahui efektifitas mekanisme koping terhadap tingkat kecemasan pada pasien gagal ginjal kronik dalam menjalani terapi hemodialisa di Ruang Hemodialisa RSUD. Dr. Pirngadi Medan Tahun 2020. Jenis penelitian bersifat Deskriptif Analitik dengan desain Cross Sectional. Metode pengambilan sampel dengan Tekhnik Purposive Sampling, besar sampel yang diteliti sebanyak 37 orang. Dari hasil uji statistik ChiSquare dengan tingkat kemaknaan 95\% dengan menggunakan program SPSS menunjukkan bahwa ada efektifitas yang bermakna antara mekanisme koping terhadap tingkat kecemasan pasien yakni koping dukungan sosial dengan nilai $p=0,02<0,05$ dan sumber spiritual dengan nilai $p=0,01<0,05$. Mekanisme koping dukungan sosial dan sumber spiritual memiliki efektifitas terhadap tingkat kecemasan pasien. Ini menunjukkan bahwa dukungan sosial dan sumber spiritual pasien yang kurang akan mempengaruhi gangguan mental sehingga menimbulkan kecemasan. Disarankan Bagi pasien gagal ginjal kronik yang menjalani terapi hemodialisa agar lebih banyak mencari informasi, baik dari media cetak maupun elektronik sehingga lebih tahu tentang pelayanan.
\end{abstract}

Kata Kunci : Koping pasien, Tingkat Kecemasan, Hemodialisa

\section{PENDAHULUAN}

Gagal ginjal kronik makin banyak menarik perhatian dan makin banyak dipelajari, karena walaupun sudah mencapai tahap gagal ginjal terminal, penderita masih dapat hidup panjang dengan kualitas hidup yang cukup baik bahkan baik. Yang disebut dengan gagal ginjal terminal adalah keadan dimana ginjal sudah tidak dapat menjalankan fungsinya lagi. (Lumenta, 1992).

Gagal ginjal merupakan penurunan fungsi yang terjadi secara akut maupun kronis. Dikatakan gagal ginjal akut bila penurunan fungsi ginjal berlangsung secara tiba-tiba dan dalam waktu relatif singkat (bebeapa hari atau beberapa minggu). Sedangkan gagal ginjal kronik gejalanya muncul secara bertahap dan memakan waktu yang lama (umumnya tahunan). Gagal ginjal kronik sering tidak menunjukkan gejala awal yang jelas. Keluhan baru muncul setelah fungsi ginjal turun lebih dari 10\% s/d 25\% (Japaries, 1992).

Pasien-pasien yang lebih muda sering khawatir terhadap perkawinan dan anak-anak yang dimilikinya dan beban yang ditimbulkan pada keluarga mereka (Brunner \& Suddarth, 2005).

Indonesia termasuk negara dengan tingkat penderita gagal ginjal yang cukup tinggi, diperkirakan setiap tahun 480 orang mengalami gagal ginjal, dan diperkirakan jumlah pasien gagal 
Vol. 15 No. 1 Januari - April 2020

ginjal bertambah sekitar 100 orang penderita baru setiap satu juta penduduk pertahun (Tessy, 1998). Dan jumlah penderita penyakit gagal ginjal akhirakhir ini cenderung meningkat. Kasus ini terjadi antara lain akibat perubahan pola hidup misalnya biasanya meminum alcohol, makanan yang tinggi kolesterol, merokok, obat-obatan yang tidak sesuai dengan dosis, kurang mengkonsumsi air (Surya, 2011).

Berdasarkan hasil penelitian yang terdapat di Sumatera Utara tahun 2009 diketahui yang menderita penyakit gagal ginjal yang mengalami rawat jalan sebanyak 480 orang dan jumlah angka kematian pada penderita penyakit gagal ginjal sebanyak 82 orang (Profil Kesehatan Indonesia, 2010).

Dalam melakukan tindakan hemodialisa segala yang mungkin dan sering dijumpai pada pasien adalah cemas. Cemas atau ansietas adalah respon tanpa objek yang spesifik yang secara subjektif dialami dalam kehidupan secara interpersonal dan merupakan bagian dari kehidupan sehari-hari dimana menghasilkan peringatan yang berharga dan penting upaya memelihara keseimbangan diri dan lingkungan (Suliswati, 2005).

Dengan demikian diperlukan suatu mekanisme pertahanan diri yang dapat mengontrol kecemasan yang ada sehingga pasien dapat dengan tenang menjalani terapi hemodialisa. Ketidakmampuan mengatasi ansietas secara konstruktif merupakan penyebab utama tejadinya perilaku patologis (Stuart, 2007).

Koping merupakan salah satu standar upaya tubuh untuk menyelesaikan suatu masalah yang dihadapi, penyesuaian dengan lingkungan Rumah Sakit. Dimana bagi pasien yang menghadapi hemodialisa merupakan hal asing dan dapat menimbulkan kecemasan, demikian juga halnya interaksi dengan berbagai tenaga kesehatan juga peralatan-peralatan rumah sakit yang masih asing bagi pasien pre hemodialisa yang pertama kali (Stuart, 2007).

\section{METODE PENELITIAN}

Jenis penelitian ini adalah bersifat deskriptif analitik, yaitu penelitian yang mencoba menggali bagaimana dan mengapa fenomena kesehatan itu terjadi. Kemudian melakukan analisis dinamika korelasi antara fenomena atau antara faktor risiko dengan faktor efek. Yang dimaksud faktor efek adalah suatu akibat dari adanya faktor risiko, sedangkan faktor risiko adalah suatu fenomena yang mengakibatkan terjadinya efek/pengaruh (Notoatmodjo, 2010). Penelitian ini menggunakan desain cross sectional yaitu merupakan rancangan penelitian yang pengukuran atau pengamatannya dilakukan secara simultan pada satu saat atau sama sekali waktu (Alimul,2007).

\section{LOKASI DAN WAKTU PENELITIAN}

Penelitian ini dilakukan di Ruang Hemodialisa RSUD Dr. Pirngadi Medan. Penelitian ini dilakukan tahun 2020.

\section{POPULASI DAN SAMPEL PENELITIAN Populasi}

Populasi merupakan keseluruhan subjek atau objek dengan karakteristik tertentu yang akan diteliti. (Notoatmodjo, 2011).

Populasi dalam penelitian ini adalah semua pasien penderita gagal ginjal yang baru pertama kali menjalani terapi hemodialisa di RSUD. Dr. Pirngadi Medan.

\section{Sampel}

Penelitian ini menggunakan teknik purposive sampling yaitu seluruh penderita gagal ginjal yang baru pertama kali menjalani terapi hemodialisa di Ruang Hemodialisa RSUD. Dr. Pirngadu Medan Medan tahun 2020.

Adapun kriteria inklusi sampel yang digunakan dalam penelitian ini adalah :

a. Pasien yang baru pertama kali hemodialisa.

b. Dapat berkomunikasi dan membaca.

c. Bersedia untuk diwawancarai yang dinyatakan secara tertulis dengan menandatangani surat perjanjian peserta penelitian.

\section{HASIL DAN PEMBAHASAN}

\section{A. HASIL PENELITIAN}

\section{Optimis Mengenai Masa Depan}

Tabel 1. Distribusi Frekuensi Tingkat Kecemasan Responden Berdasarkan Optimis terhadap Masa Depan pada Pasien Gagal Ginjal Kronik dalam Menjalani Hemodialisa di Ruang Hemodialisa RSUD. Dr. Pirngadi Medan Tahun 2020

\begin{tabular}{cccc}
\hline No & $\begin{array}{c}\text { Optimis terhadap } \\
\text { Masa Depan }\end{array}$ & f & \% \\
\hline 1 & Efektif & 5 & 13,5 \\
2 & Kurang efektif & 19 & 51,4
\end{tabular}




\begin{tabular}{cccc}
3 & Tidak efektif & 13 & 35,1 \\
\hline Total & 37 & 100 \\
\hline
\end{tabular}

Berdasarkan tabel 1 diatas dapat dilihat bahwa responden dalam menghadapi hemodialisa yang menggunakan koping dengan optimis terhadap masa depan kurang efektif dengan jumlah 19 responden $(51,4 \%)$.

\section{Dukungan Sosial}

Tabel 2. Distribusi Frekuensi Tingkat Kecemasan Responden Berdasarkan Dukungan Sosial Pasien Gagal Ginjal Kronik dalam menjalani Hemodialisa di Ruang Hemodialisa RSUD Dr. Pirngadi Medan Tahun 2020.

\begin{tabular}{cccc}
\hline No & Dukungan Sosial & f & \% \\
\hline 1 & Efektif & 1 & 2,7 \\
2 & Kurang efektif & 9 & 24,3 \\
3 & Tidak efektif & 27 & 73,0 \\
\hline & Total & 37 & 100
\end{tabular}

Berdasarkan tabel 2 diatas dapat dilihat bahwa mekanisme koping berdasarkan Dukungan Sosial tidak efektif dengan jumlah 27 responden $(73,0 \%)$.

\section{Sumber Spiritual}

Tabel 3. Distribusi Frekuensi Tingkat Kecemasan Responden Berdasarkan Sumber Spiritual Pasien Gagal Ginjal Kronik dalam menjalani Hemodialisa di Ruang Hemodialisa RSUD Dr. Pirngadi Medan Tahun 2020.

\begin{tabular}{cccc}
\hline No & $\begin{array}{c}\text { Sumber } \\
\text { Spiritual }\end{array}$ & f & \% \\
\hline 1 & Efektif & 1 & 2,7 \\
2 & Kurang efektif & 15 & 40,6 \\
3 & Tidak efektif & 21 & 56,7 \\
\hline & Total & 37 & 100 \\
\hline
\end{tabular}

Berdasarkan tabel 3 diatas, dapat dilihat bahwa responden dalam menghadapi terapi hemodialisa memiliki dukungan spiritual tidak efektif dengan jumlah 21 responden $(56,7 \%)$.

\section{Mengontrol Situasi maupun Perasaan}

Tabel 4. Distribusi Frekuensi Tingkat Kecemasan Responden Berdasarkan Mengontrol Situasi maupun Perasaan Pasien Gagal Ginjal Kronik dalam menjalani Hemodialisa di Ruang Hemodialisa RSUD Dr. Pirngadi Medan Tahun 2020.

\begin{tabular}{cccc}
\hline No & $\begin{array}{c}\text { Mengontrol Situasi } \\
\text { maupun Perasaan }\end{array}$ & f & \% \\
\hline 1 & Efektif & 13 & 35,1 \\
2 & Kurang efektif & 15 & 40,6 \\
3 & Tidak efektif & 9 & 24,3
\end{tabular}

\begin{tabular}{rrr}
\hline Total & 37 & 100 \\
\hline
\end{tabular}

Berdasarkan tabel 4 diatas, dapat dilihat bahwa responden dalam menghadapi terapi hemodialisa yang menggunakan koping dengan mengontrol situasi dan perasaan, kurang efektif dengan jumlah 15 responden (40,6\%).

\section{Menerima Kenyataan}

Tabel 5. Distribusi Frekuensi Tingkat Kecemasan Responden Berdasarkan Menerima Kenyataan Pasien Gagal Ginjal Kronik dalam menjalani Hemodialisa di Ruang Hemodialisa RSUD. Dr. Pirngadi Medan Medan Tahun 2020.

\begin{tabular}{cccc}
\hline No & $\begin{array}{c}\text { Menerima } \\
\text { Kenyataan }\end{array}$ & $\mathbf{f}$ & $\mathbf{\%}$ \\
\hline 1 & Efektif & 16 & 43,2 \\
2 & Kurang efektif & 16 & 43,2 \\
3 & Tidak efektif & 5 & 13,6 \\
\hline & Total & 37 & 100 \\
\hline
\end{tabular}

Berdasarkan tabel 5 diatas dapat dilihat bahwa responden dalam menghadapi terapi hemodialisa dengan koping menerima kenyataan memiliki kategori yang sama antara efektif dan kurang efektif yaitu masing-masing sebanyak 16 responden $(43,2 \%)$.

\section{Tingkat Kecemasan}

Tabel 6. Distribusi Frekuensi Tingkat Kecemasan Pasien Gagal Ginjal Kronik dalam menjalani Hemodialisa di Ruang Hemodialisa RSUD Dr. Pirngadi Medan Tahun 2020.

\begin{tabular}{cccc}
\hline No & $\begin{array}{c}\text { Tingkat } \\
\text { Kecemasan }\end{array}$ & f & \% \\
\hline 1 & Ringan & 0 & 0 \\
& & & \\
2 & Sedang & 4 & 10,8 \\
3 & Berat & 4 & 10,8 \\
4 & Panik & 29 & 78,4 \\
\hline & Total & 37 & 100 \\
\hline
\end{tabular}

Berdasarkan tabel 6 diatas dapat dilihat bahwa mayoritas responden dalam menjalani terapi hemodialisa mengalami Kecemasan berat sekali/ Panik dengan jumlah 29 orang $(78,4 \%)$.

Tabel 7. Rekapitulasi Hasil Uji Chi Square Efektifitas Mekanisme Koping terhadap Tingkat Kecemasan pada Pasien Gagal Ginjal Kronik dalam Menjalani Hemodialisa di Ruang 
Vol. 15 No. 1 Januari - April 2020

Hemodialisa RSUD. Dr. Pirngadi Medan Tahun 2020 .

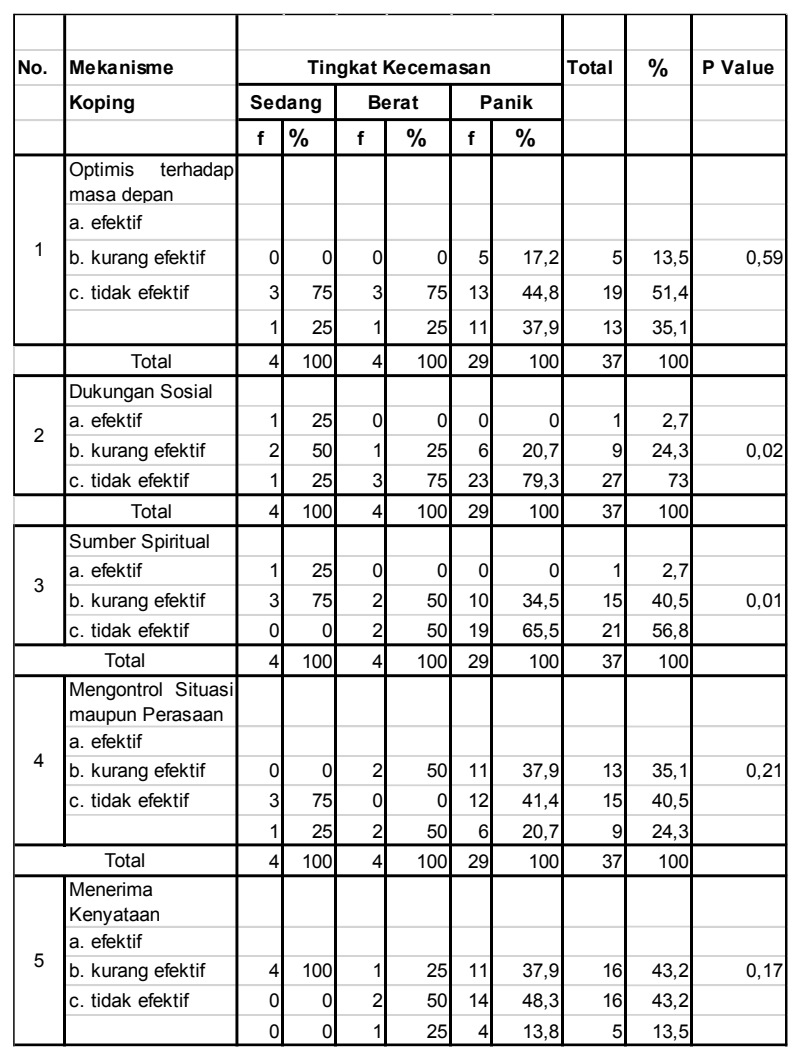

Berdasarkan tabel 7 di atas, dapat dilihat bahwa mekanisme koping pasien dengan tingkat kecemasan menunjukkan adanya efektifitas yang bermakna pada dukungan sosial dan sumber spiritual dengan tingkat kecemasan pasien dalam menjalani hemodialisa, diperoleh nilai $p$ value 0,02 dan $0,01 \quad(p<0,05)$, dimana mayoritas responden mengalami cemas berat sekali (panik).

\section{PEMBAHASAN}

\section{Efektifitas Mekanisme Koping Optimis terhadap Masa Depan terhadap Tingkat Kecemasan}

Menurut Jaloweic, 1993 dalam Brunner \& Suddarth (2001), menjelaskan bahwa keyakinan dan penerimaan pasien terhadap suatu tindakan pengobatan dapat mempengaruhi tingkat stress dan kecemasan. Namun kecemasan terjadi apabila pasien tidak yakin dan menerima terapi hemodialisa yang akan dilakukan kepadanya.

\section{Efektifitas Mekanisme Koping Dukungan Sosial terhadap Tingkat Kecemasan}

Hal ini sesuai dengan pendapat Dadang Hawari (2001), bahwa hubungan antara sesame manusia yang tidak baik dapat merupakan sumber stress dan cemas karena dukungan sosial merupakan suatu tatanan hubungan yang sangat berarti bagi seseorang yang bersumber dari luar diri individu tersebut, dimana dukungan sosial dapat berasal dari keluarga, teman dan tetangga ataupun tokoh masyarakat.

\section{Efektifitas Mekanisme Koping Sumber Spiritual terhadap Tingkat Kecemasan \\ Menurut Roberts A. Emmons, The} Psychology of Ultimate Concerns, karakteristik orang yang cerdas menggunakan sumber spiritual adalah orang-orang yang :

- Mampu untuk mentransendensikan yang fisikal dan material

- Mampu untuk mensakralkan pengalaman sehari-hari

- Mampu untuk menggunakan sumber-sumber spiritual untuk menyelesaikan masalah dan kemampuan untuk berbuat baik.

\section{Efektifitas Mekanisme Koping Mengontrol} Situasi maupun Perasaan terhadap Tingkat Kecemasan

Menurut Jaloweic (1993) dalam Brunner \& Suddarth (2001), menjelaskan bahwa koping mengontrol situasi dan perasaan pasien sangat perlu diperhatikan dimana hal ini dapat menyebabkan ketegangan pada pasien yang akan menghadapi hemodialisa karena adanya tekanantekanan yang memicu timbulnya kecemasan.

\section{Efektifitas Mekanisme Koping Menerima Kenyataan terhadap Tingkat Kecemasan}

Menurut Jaloweic (1993), menyatakan bahwa menerima kenyataan memang suatu hal yang sulit dilakukan dan hal ini sangat berpengaruh dalam terapi hemodialisa dimana pasien sulit menerima komplikasi, efek ataupun resiko yang mungkin terjadi pasca hemodialisa.

\section{KESIMPULAN DAN SARAN}

\section{Kesimpulan}

1. Tidak ada efektifitas mekanisme koping (optimis terhadap masa depan, mengontrol situasi maupun perasaan dan menerima kenyataan) terhadap tingkat kecemasan, dari ketiga koping tersebut mayoritas responden tidak menunjukkan adanya efektifitas koping terhadap tingkat kecemasan dalam menjalani terapi hemodialisa. 
2. Mekanisme koping dukungan sosial dan sumber spiritual memiliki efektifitas terhadap tingkat kecemasan pasien. Ini menunjukkan bahwa dukungan sosial dan sumber spiritual pasien yang kurang akan mempengaruhi gangguan mental sehingga menimbulkan kecemasan.

\section{Saran}

1. Bagi pihak RSUD. Dr. Pirngadi Medan khususnya di Ruang Hemodialisa agar lebih meningkatkan pelayanan keperawatan dan asuhan keperawatan pada pasien yang mengalami suatu penyakit dan diharuskan menjalani terapi hemodialisa.

2. Bagi pasien gagal ginjal kronik yang menjalani terapi hemodialisa agar lebih banyak mencari informasi, baik dari media cetak maupun elektronik sehingga lebih tahu tentang pelayanan.

3. Bagi keluarga pasien diharapkan selalu memberikan dukungan dan respon positif bagi pasien baik dukungan sosial maupun sumber spiritual untuk mengurangi tingkat kecemasan yang dialami pasien.

4. Bagi peneliti lain diharapkan dapat meneruskan penelitian ini agar mendapatkan hasil yang lebih maksimal.

\section{DAFTAR PUSTAKA}

Alimul, 2007. Riset Keperawatan dan Teknik Penulisan Ilmiah, Salemba Medika : Jakarta

Anna B. Keliat, 1999. Penatalaksanaan Stres, EGC : Jakarta
Brunner dan Suddarth, 2005. Keperawatan Medikal Bedah, Edisi 8, Vol.2. EGC : Jakarta

Hawari D, 2008. Manajemen Stress, Cemas, dan Depresi. EGC : Jakarta

Hidayat, 2004. Model Konsep dan Teori Keperawatan. EGC : Jakarta

Japariess W, 1992. Penyakit Ginjal. ARCAN : Jakarta

Lumenta N, 1992. Penyakit Ginjal. Gunung Mulia : Jakarta

Notoatmodjo S, 2007. Metode Penelitian Kesehatan. Rineka Cipta : Jakarta

Rasmun, 2001. Keperawatan Kesehatan Mental Psikiatri Terintegrasi dengan Keluarga, Edisi I. CV. Sagung Seto : Jakarta

Stuart G.W, 2007. Keperawatan Jiwa. EGC : Jakarta

Sudjana, 2002. Riset Keperawatan. Rineka Cipta : Bandung

Suliswati, dkk. 2005. Konsep Dasar Keperawatan Kesehatan Jiwa. EGC : Jakarta

http:///www.Indonesia.com. Depresi Gagal Ginjal, Sriwijaya, 2003

http:///www.aa-Ginjal. Blogspot.com.2009

http:///www.suaramerdeka .com.Hemodialisa, 2004

http://www.google.com. Profil Kesehatan Kota Medan tahun 2012. Diperoleh tanggal 12 April 2012 